Proceedings

\title{
A 20-year Analysis of the Evolution of Automatic Milking Systems: Processes, Technologies and Livestock Environment ${ }^{\dagger}$
}

\author{
Alessia Cogato ${ }^{1}$, Marta Brščić ${ }^{2}$, Francesco Marinello ${ }^{1}$, and Andrea Pezzuolo ${ }^{1 *}$ \\ 1 Department of Land, Environmental, Agriculture and Forestry, University of Padova, 35020 \\ Legnaro (PD), Italy; alessia.cogato.1@phd.unipd.it; francesco.marinello@unipd.it \\ andrea.pezzuolo@unipd.it; \\ 2 Department of Animal Medicine Production and Health (MAPS), University of Padova, 35020 \\ Legnaro (PD), Italy; marta.brscic@unipd.it \\ * Correspondence: andrea.pezzuolo@unipd.it \\ + Presented at the 1st International Electronic Conference on Animals - Global Sustainability and \\ Animals: Science, Ethics and Policy, 5 - 20 December 2020. \\ Available online: https://ieca2020.sciforum.net/
}

Keywords: Animal System; Automatic Milking Systems; Animal Health; Sustainability

\begin{abstract}
Over the last 20 years, the dairy industry has implemented new technologies related to Automatic Milking Systems (AMS). AMS have the potential to maximise milk production and animals' welfare, thanks to the voluntary milking access, but also to increase the resource efficiency and environmental sustainability of dairy farms. This study assesses the state of the art of research on AMS through a systematic review of patent trends in the last two decades. Patents of the last 20years were extracted from the EspaceNet database. Terms appearing in title and abstract of a total of 154 patents were processed by text mining approach, ignoring low-frequency and meaningless words, and including stemming analysis to aggregate variant forms of the same word. Four clusters were identified: Components, Sensors, Process and Animal. The results showed that the highest number of patents was yielded in the early 2000s, thus indicating the great interest to AMS in the initial period. The clusters trend pointed out that the focus on the animal and the sensing technologies was constant over time. In recent years, the priority of research shifted towards process efficiency and components. Detailed analysis of clusters allowed to appreciate an increasing interest in the animal health and body conditions over time $+249 \%$ and $+391 \%$ from 2000 to 2019 , respectively). The processes which showed increasing relevance were the ones related to facilities cleaning (+291\%). The new sensing technologies focus primarily on imaging, allowing to develop new decision models $(+348 \%)$. Results suggest that AMS patents are moving their attention towards more efficient and sustainable systems. This trend represents an important opportunity for a significant increase in the sustainability of the dairy sector, not only for animals but also for the farmers through the efficient use of the resources, thus enhancing the perception of sustainability by the consumer.
\end{abstract}

\section{Introduction}

The use of automatic technologies is a growing trend in the livestock industry [1; 2], and play a key role in future prospects [3]. Automatic Milking Systems (AMS) are one of 
the most significant technological changes in the dairy industry [4], and the number of commercial farms milking with AMS has increased rapidly in the last few years [5]. In fact, from 2011 to 2014, around 25,000 farms have installed an AMS [6], and nowadays, they can be considered as a well-established technology [7]. AMS have the potential to maximise milk production and animals' welfare, thanks to the voluntary milking access, but also to increase the resource efficiency and environmental sustainability of dairy farms [8;9].

This study assesses the state of the art of research on AMS through a systematic review of patent trends in the last two decades (2000-2019) in order to identify research tendencies and critical gaps. 154 patents were extracted from the EspaceNet database and processed by a text mining approach.

\section{Methods}

The systematic review was carried out extracting the patents of the last 20 years from the patent server EspaceNet (www.epo.org). Patents were searched using different synonyms to define the AMS and filtered by publication date (2000-2019). Once extracted, the patents were organised in five groups of four years.

The content of "Title" and "Abstract" were processed with the text mining process. Analyses were carried out using Microsoft Excel and GraphPad Prism 8.0.0 (GraphPad Software, Inc.; La Jolla, CA, USA). Titles and Abstract were pre-processed to improve the quality of information retrieval [10;11]. Meaningless features, such as punctuation marks, numbers and symbols, were removed applying a tokenisation process. The list of single words resulting from tokenisation was further perfected by deleting the low-frequency words and connectors. Finally, the word-sense disambiguation and the stemming processes were applied. These processes allowed clarifying the ambiguity of acronyms and including in a single lemma all variant forms of the same word.

After the pre-processing, the words included in the dataset were grouped into four clusters: "Animal", "Process", "Sensors" and "Components". First, the trend of the four clusters over the years was analysed. Then, a words frequency analysis was carried within each cluster to identify the patent trend tendencies. Frequency analysis was also applied to the Applicants to determine the top contributing countries.

\section{Results and Discussion}

The trend of the patents awarded over time is reported in Figure 1. The chart reports the number of patents starting from 1996, as the employment of AMS in the farms dates to the '90s. The number of patents reached the maximum number in 1998-1999 when the first Voluntary Milking Systems were commercialised [12]. After a sharp decrease, the patent registration has stabilised, despite natural oscillations.

The highest number of patents was granted by the Netherlands (33.6 \%), followed by Sweden (14.3\%) and China (9.7\%). 


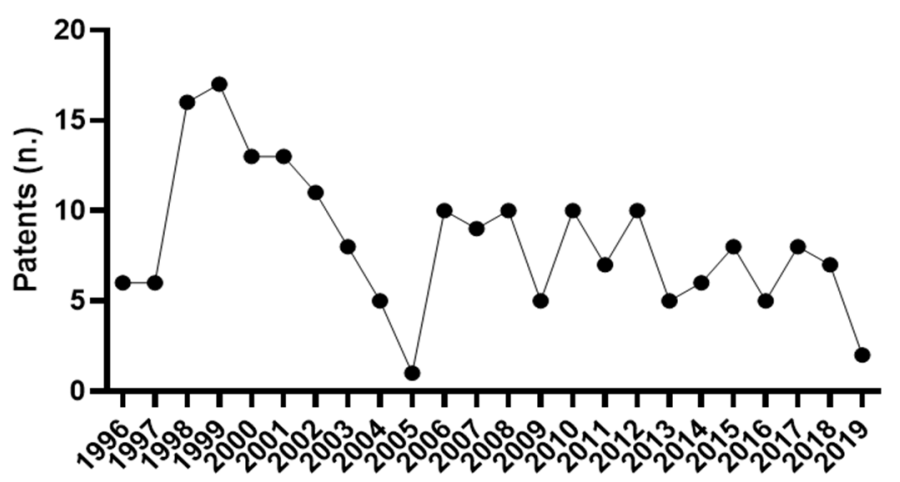

Period

Figure 1. The trend of the patents per year.

The text mining process allowed to identify the following main clusters: Components, Sensors, Process, Animal, weighting $30 \%, 29 \%, 25 \%$ and $16 \%$, respectively. As reported in Figure 2, the trend of the clusters was not constant over the 20 years. Initially, the research focused on sensors to support high-technology milking systems [13]. In the last 10-years, the development of sensors has been incorporated in the improvement of the process efficiency. Meanwhile, the target of the patents moved towards the components.

\section{Cluster trend}

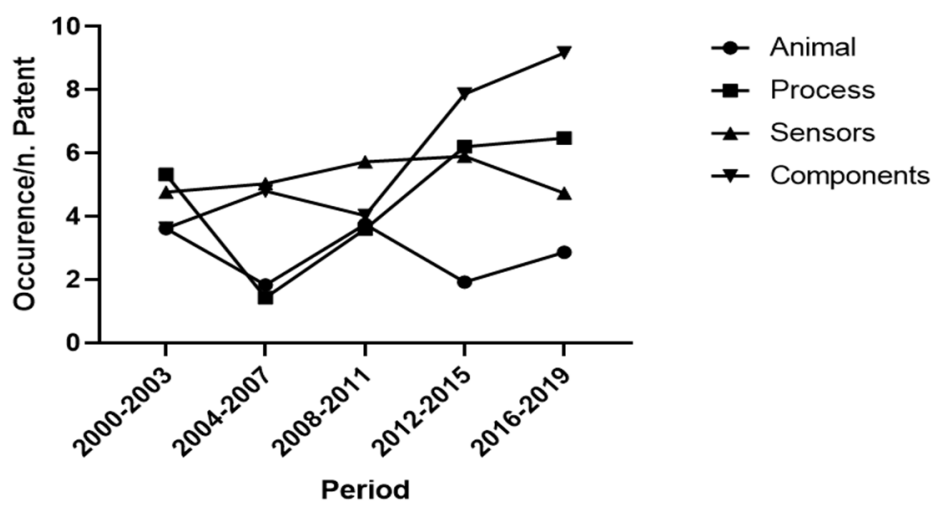

Figure 2. Trend of the four clusters during the observed period.

As concerns the single clusters, the frequency analysis of cluster "Animals" showed that, after the initial implementation of the feeding, recently the interest focused on the dairy barn. Moreover, more consideration was given to the animal body condition/weight and health (+249\% and $+391 \%$ from 2000 to 2019, respectively). To maintain high-efficiency production and ensure animal welfare, health-monitoring equipment is strongly required [14], and the evolution of the AMS involved also automated weighing scales [15] and, more recently, optical-based techniques [2].

To confirm these findings, the topic with the highest increase in the last decade within the cluster "Sensors" was related to imaging techniques. Models are strictly connected with sensing technologies, which support farmers' decision making. In fact, the models had $348 \%$ increase from 2000 to 2019. 
As regards the cluster "Process", the analysis highlighted the increasing relevance of the management of the facilities cleaning operations. For example, the word "water" increased rapidly from 2000 to 2019 (+291\%). Moreover, the implementation of the pulsation technologies ("pulsation" $+65 \%$ from 2000 to 2019) reflects the evolution toward more efficient milking units, ensuringthe udder health [16].

Within the cluster "Components", the word frequency analysis showed that the industry spent the first decade perfecting the teat cups (-44\% from 2000 to 2019), while the second decade focused on storage systems, e.g. improving tanks and pumps. Moreover, in the second decade, several patents were registered about the milking arm.

\section{Conclusions}

This study analysed the AMS patents trend over the last two decades. The systematic review approach allowed to identify research tendencies and gaps. Cluster analysis showed that the AMS industry is focused on the implementation of more efficient and sustainable systems. The evolution of components, sensors and technologies complies both with high-quality products and ensure animal welfare. Topics related to the animal aspect are still underdeveloped, but their increasing trend allows to expect a progressive evolution in the animal welfare issue.

\section{References}

1. Da Borso, F.; Chiumenti, A.; Sigura, M.; Pezzuolo, A. Influence of automatic feeding systems on design and management of dairy farms. Journal of Agricultural Engineering, 2017, 48-52.

2. Pezzuolo, A., Milani, V., Zhu, D., Guo, H., Guercini, S., Marinello, F. On-Barn pig weight estimation based on body measurements by structure-from-motion (SfM). Sensors, 2018, 18(11), 3603.

3. de Koning, K.; van der Vost, Y.; Meijering A. Automatic milking experience and development in Europe. Wageningen Academic Publishers, Wageningen, the Netherlands, 2002, 1-11.

4. Hogeveen, H.; Ouweltjes, W.; de Koning, CJAM.; Stelagen K. Milking interval, milk production and milk flowrate in an automatic milking system. Livest. Prod. Sci., 2001, 72, 157-167.

5. Klungel, G. H.; Slaghuis, B. A.; Hogeveen, H. The effect of the introduction of automatic milking systems on milk quality. J Dairy Sci, 2000, 83(9), 1998-2003.

6. Lessire, F.; Moula, N.; Hornick, J.L.; Dufrasne, I. Systematic Review and Meta-Analysis: Identification of Factors Influencing Milking Frequency of Cows in Automatic Milking Systems Combined with Grazing. Animals, 2020, 10(5), 913.

7. Hansen, B. G.; Stræte, E. P. Dairy farmers' job satisfaction and the influence of automatic milking systems. NJAS-Wageningen Journal of Life Sciences, 2020, 92, 100328.

8. Hansen, B.G.; Bugge, C.T.; Skibrek, P.K. Automatic milking systems and farmer wellbeingexploring the effects of automation and digitalization in dairy farming. J. Ru Study, 2020, in press

9. Mattachini, G.; Pompe, J.; Finzi, A.; Tullo, E.; Riva, E.; Provolo, G. Effects of feeding frequency on the lying behavior of dairy cows in a loose housing with automatic feeding and milking system. Animals, 2019, 9(4), 121.

10. Kannan, S.; Gurusamy, V. Preprocessing Techniques for Text Mining. IJCSC 2014, 5, 7-16.

11. Cogato, A.; Meggio, F.; De Antoni Migliorati, M.; Marinello, F. Extreme weather events in agriculture: A systematic review. Sustain. 2019, 11, 1-18. 
12. Kashiwamura, F. Development and Current State of the Milking Robot in Japan and Europe. Anim. Sci. J. 2000, 71, 445-453.

13. Hogeveen, H.; Ouweltjes, W. Sensors and management support in high-technology milking. J. Anim. Sci. 2003, 81 Suppl 3, 1-10.

14. Song, X.; Bokkers, E.A.M.; van der Tol, P.P.J.; Groot Koerkamp, P.W.G.; van Mourik, S. Automated body weight prediction of dairy cows using 3-dimensional vision. J. Dairy Sci. 2018, 101, 4448-4459.

15. Alawneh, J.I.; Stevenson, M.A.; Williamson, N.B.; Lopez-Villalobos, N.; Otley, T. Automatic recording of daily walkover liveweight of dairy cattle at pasture in the first 100 days in milk. J. Dairy Sci. 2011, 94, 4431-4440.

16. Kaskous, S. Optimization of the Pulsation Ratio During the Course of Milk Removal after using A Quarter Individual Milking System “MultiLactor." Int. J. Agric. Res. 2018, 6, 284-289. 